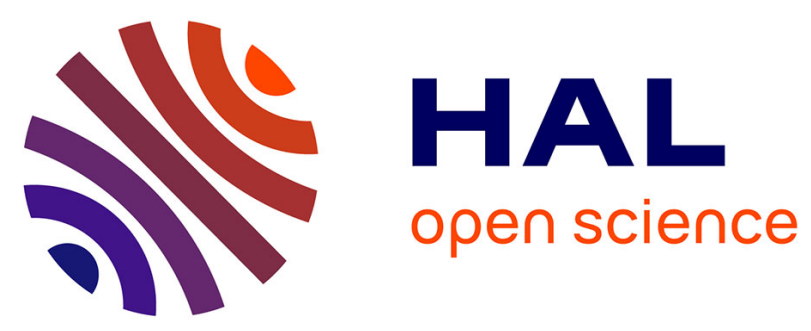

\title{
Self-disinfecting PDMS surfaces with high quaternary ammonium functionality by direct surface photoinitiated polymerization of vinylbenzyl dimethylbutylammonium chloride
}

\author{
Yuzhen Lou, Damien Schapman, Dimitri Mercier, Stephane Alexandre, \\ Fabrice Burel, Pascal Thebault, Nasreddine Kébir
}

\section{To cite this version:}

Yuzhen Lou, Damien Schapman, Dimitri Mercier, Stephane Alexandre, Fabrice Burel, et al.. Selfdisinfecting PDMS surfaces with high quaternary ammonium functionality by direct surface photoinitiated polymerization of vinylbenzyl dimethylbutylammonium chloride. European Polymer Journal, 2021, 152, pp.110473. 10.1016/j.eurpolymj.2021.110473 . hal-03361056

\author{
HAL Id: hal-03361056 \\ https://hal.science/hal-03361056
}

Submitted on 1 Oct 2021

HAL is a multi-disciplinary open access archive for the deposit and dissemination of scientific research documents, whether they are published or not. The documents may come from teaching and research institutions in France or abroad, or from public or private research centers.
L'archive ouverte pluridisciplinaire HAL, est destinée au dépôt et à la diffusion de documents scientifiques de niveau recherche, publiés ou non, émanant des établissements d'enseignement et de recherche français ou étrangers, des laboratoires publics ou privés. 


\title{
Self-disinfecting PDMS surfaces with high quaternary ammonium functionality by direct surface photoinitiated polymerization of vinylbenzyl dimethylbutylammonium chloride.
}

\author{
Yuzhen Lou ${ }^{1}$, Damien Schapman ${ }^{2}$, Dimitri Mercier ${ }^{3}$, Stéphane Alexandre ${ }^{4}$, Fabrice Burel ${ }^{1}$, Pascal \\ Thebault ${ }^{4}$, Nasreddine Kébir ${ }^{1}$
}

\begin{abstract}
${ }^{1}$ Normandie Université, INSA Rouen Normandie, Laboratoire PBS, UMR CNRS 6270 \& FR 3038, Avenue de l'Université, 76801 Saint Etienne du Rouvray, France

${ }^{2}$ Normandie Université, UNIROUEN, IFR MP 23, PRIMACEN, 76821 Mont-Saint-Aignan, France

${ }^{3}$ PSL Research University, Chimie ParisTech - CNRS, Institut de Recherche de Chimie Paris, 11 rue Pierre et Marie Curie, 75005 Paris, France

${ }^{4}$ Normandie Université, UNIROUEN, laboratoire PBS, UMR CNRS 6270 \& FR 3038, 76821 Mont-SaintAigan, France
\end{abstract}

\begin{abstract}
Vinylbenzyl dimethylbutylammonium chloride was successfully grafted and photopolymerized from a PDMS surface, in presence of benzophenone. The obtained surface exhibited quaternary ammonium density above $10^{7}$ charge $/ \mathrm{cm}^{2}$ and very high hydrophilicity compared to ungrafted surfaces. Bacterial enumeration and fluorescence microscopy revealed an efficient contact killing of this surface against Escherichia coli, Staphylococcus aureus and Staphylococcus epidermidis.
\end{abstract}

Keywords: Quaternary ammonium; photo; grafting from; PDMS; bactericidal, antibacterial.

Corresponding authors: nasreddine.kebir@insa-rouen.fr ; pascal.thebault@univ-rouen.fr 


\section{Introduction}

Planktonic bacteria or early attached cells are sensitive to environmental factors while bacteria in biofilms are more resistant. Indeed, it has been reported that antibiotic concentrations required to effectively eradicate biofilm bacteria are 100 to 1000 times higher than for planktonic bacteria. Therefore, it is suggested that preventing bacterial adhesion on material surfaces is a key property to avoid biofilm formation and microbial contamination [1-2].

There are three kinds of antibacterial surfaces: anti-adhesive or bacteriophobic surfaces that resist microbial adhesion [3-8] ; release-based surfaces, which kill both adhered and planktonic bacteria by leaching antibacterial agents [9-11] and contact-killing surfaces bearing cationic groups that attract and kill bacteria by disrupting their cell membrane [12-13]. However, the antibacterial activity of release coatings is limited in time and overuse of antibiotics can lead to the phenomenon of bacterial resistance [14].

Polymer-based antibacterial agents called antibacterial polymers have more advantages over low molecular weight antibacterial agents, contributing not only to their non-volatile and chemically stable structure, but also to their ease of use [15]. Polycationic polymers especially quaternary ammonium (QA)-based polymers, are ones of the most efficient antibacterial polymers. Indeed, QA compounds exhibit extensive antimicrobial activity against bacteria, fungi, parasites and lipophilic viruses [16-18]. The hydrophilic-hydrophobic balance and molecular weight of the polymer, as well as the length of the alkyl chains attached to the nitrogen atom of the QA moieties, have been found to significantly affect their antimicrobial activity [19-22].

Thanks to their high flexibility, hydrophobicity, chemical and thermal stability and biocompatibility, silicone materials are widely used in medical field including orthopedic application (e.g., the hand and foot joint implants), catheters, extracorporeal equipment (e.g., blood oxygenator, thermal bypass machines and kidney dialysis) and aesthetic implants (e.g., silicone breast implant) etc. [23-29]. Nonetheless, its hydrophobicity easily exposes it to protein adsorption, bacterial contamination and biofilm formation, which limits its use due to serious health and economic implications [30-32].

Covalent grafting of antibacterial polymers onto silicone surfaces is one of the most important and promising strategies to avoid contamination and/or biofouling. Due to the chemical stability and inertness of PDMS, direct chemical modification is difficult to realize. Often, plasma treatment is performed on PDMS surface to generate functional anchoring sites such as hydroxyl groups, which 
provide high hydrophilicity to the surface [33]. However, the post-chemical coupling must be achieved rapidly after a few minutes due to the recovery of hydrophobicity of plasma-treated PDMS surfaces, which results from the high dynamics of PDMS macromolecular chains and the diffusion of hydroxyl groups into the bulk [34].

In the last two last decades, some chemical routes have been developed to functionalize PDMS surfaces and to modify their properties [35-43]. One of the most used strategy is the coupling reaction by hydrosilylation between the surface $\mathrm{Si}-\mathrm{H}$ groups and carbon-carbon double bonds from bioactive polymers or molecules [35-40]. Indeed, the Si-H groups present on the PDMS surface, before, during and after the hydrosilylation curing process, have been successfully used to graft bioactive copolymers onto PDMS surfaces [35-38]. Si-H groups can also be introduced to the surface by acidcatalyzed insertion of polymethylhydroxysiloxane [39-40].

Alternatively, direct chemical modification of PDMS surfaces can be also performed by photoinduced processes, using benzophenone as photo-initiator. For instance, covalent micropatterning of PDMS surface have been achieved by photo-grafting, through a mask, of acrylic acid, [41] polyethylene glycol monoacrylate and polyethylene glycol diacrylate [42]. Recently, Braden et al. developed a simultaneous photo-grafting/photo-crosslinking process to prepare antifouling PDMS substrates by coating the surface with two zwitterionic polymers: poly(sulfobetaine methacrylate) or poly(carboxybetaine methacrylate), in the presence of poly(ethylene) glycol diacrylate as crosslinker [43].

The "grafting to" and "grafting from" approaches are two major irreversible grafting methods to prepare antimicrobial surfaces by tethering functional polymers with QA functional groups [44]. In the "grafting to" approach, functionalized polymers are directly immobilized on a suitable surface under appropriate conditions. As a result, an already immobilized polymer film blocks other chains of that polymer from reaching the reactive sites on the surface, which limits the grafting density. In contrast, in the "grafting from" approach, suitable initiators are first immobilized on the surface, allowing the in situ polymerization of the monomers to form a homogeneous and dense polymer film on that surface [45].

Poly(trialkylvinylbenzyl ammonium chloride) polymers have been shown to be among the most bactericidal polymers [16-22]. Kebir et al. [35] prepared a $\operatorname{Poly}(N, N$-dimethylbutyl vinylbenzyl ammonium chloride) random copolymer bearing carbon-carbon double bounds and grafted it onto PDMS surfaces by hydrosilylation. The grafting density of the copolymer was modified by varying 
the $\mathrm{Si}-\mathrm{H}$ content by changing the curing time or the ratio between the silicone components. The resulting cationic PDMS surfaces exhibited accessible ammonium charge densities ranging from $1.8 \times 10^{14}$ to $2.8 \times 10^{15} \mathrm{~N}^{+} . \mathrm{cm}^{-2}$ and contact angle with water varying between 102 and $88^{\circ}$, respectively. For Sylgard ${ }^{1} 184$ PDMS films prepared with the conventional PartA/PartB $=1 / 10$ ratio, grafting of the copolymer after curing led to the lowest surface coverage and wettability. Nevertheless, high killing efficiency (96-100\%, respectively) against E. coli and S. epidermidis after 1 h of contact was obtained in all cases.

In this work, we describe the design of highly QA-functionalized self-disinfecting PDMS surfaces by a straightforward process consisting of direct surface photoinitiated polymerization of vinylbenzyl dimethylbutylammonium chloride in the presence of benzophenone as photo-initiator. The physico-chemical and antimicrobial properties of the modified surfaces are investigated in comparison with literature data.

\section{Experimental section}

\section{Materials}

Sylgard ${ }^{\circledR} 184$ was purchased from DOW chemical company (USA). $N, N$-dimethylbutylamine (99\%) and vinylbenzyl chloride (>90\%) were purchased from Sigma-Aldrich. Dry methanol (99.8\%) and acetone were purchased from Acros Organics. Dry diethyl ether and glass coverslip $(18 \times 18 \mathrm{~mm}$, Fisherbrand $^{\mathrm{TM}}$ ) were purchased from Thermo Fisher Scientific. Benzophenone (BP) ( $\geq 99 \%$ ) was purchased from Merck. Ultrapure water was obtained from a Milli-Q system (Siemens, France). All chemicals were used without further purification.

S. aureus (ATCC 29213), S. epidermidis (ATCC 35984) and E. coli (K12 MG1655) strains were stored as frozen aliquots in brain-heart infusion broth (BHI, Bacto, France) and $30 \%$ glycerol at $-20{ }^{\circ} \mathrm{C}$. The LIVE/DEAD bacterial viability Kit, L7007 (SYTO ${ }^{\circledR} 9$ dye, $1.67 \mathrm{mM} /$ Propidium iodide, $18.3 \mathrm{mM}$ ) was purchased form Thermo Fisher Scientific. Phosphate buffered saline (PBS), prepared from PBS tablets (Gibro, Swiss) and ultrapure water, was autoclaved before use.

\section{Preparation of vinylbenzyl dimethylbutylammonium chloride (VBAC)}

Vinylbenzyl dimethylbutylammonium chloride (VBAC) was synthesized according to a procedure described in the literature, [46-47] with some modifications. Briefly, vinylbenzyl chloride (VBC) was added dropwise to a vigorously stirred solution of $N, N$-dimethylbutylamine (DMBA) in dry methanol (5.55 mol/L) at room temperature under an inert atmosphere. The final VBC/DMBA 
molar ratio was of 1/1.5 The mixture was left to react overnight under stirring. Then, the mixture was concentrated and added dropwise into a large excess of dry diethyl ether. The precipitated product was collected by filtration and dried under vacuum. ${ }^{1} \mathrm{H}$ NMR (MHz, DMSO- $\left.d_{6}\right): \delta 7.57$ (dd, 4H), 6.79 $(\mathrm{dd}, 1 \mathrm{H}), 5.96(\mathrm{~d}, 1 \mathrm{H}), 5.39(\mathrm{~d}, 1 \mathrm{H}), 4.61(\mathrm{~s}, 2 \mathrm{H}), 3.29(\mathrm{~m}, 2 \mathrm{H}), 2.99(\mathrm{~s}, 6 \mathrm{H}), 1.76(\mathrm{~m}, 2 \mathrm{H}), 1.30(\mathrm{dt}$, 2H), 0.94 (t, 2H). FTIR-ATR ( $\left.\mathrm{cm}^{-1}\right)$ : 3069 and 3031 (=C-H stretching vibration ); 3000-2800 (C-H stretching vibration in $\mathrm{CH}, \mathrm{CH}_{2}$ and $\mathrm{CH}_{3}$ groups); 1630, 1608, $1513(\mathrm{C}=\mathrm{C}$ stretching vibration of the vinyl group and the benzene ring); 1498 ( $\mathrm{C}-\mathrm{H}$ bending vibration in $\left.\mathrm{N}^{+}-\mathrm{CH}_{2}-\mathrm{Ar}\right) ; 1463$ ( $\mathrm{C}-\mathrm{H}$ bending vibration in $\left.\mathrm{N}^{+}-\mathrm{CH}_{2}\right) ; 1440\left(\mathrm{C}-\mathrm{H}\right.$ bending vibration in $\left.\mathrm{N}^{+}-\mathrm{CH}_{3}\right) ; 1410$ (=C-H bending vibration); 1300-1000 (C-H bending vibrations in plane of the benzene ring); 1062 (C-N stretching vibration); 950-700 (C-H bending vibrations out of plane of the benzene ring).

\section{Preparation of PDMS film}

$15 \mathrm{~g}$ of a mixture of the two parts of Sylgard ${ }^{\circledR} 184$, i.e. base and curing agent, in a ratio of 10:1 $(\mathrm{w} / \mathrm{w})$, were casted into a square low-density polyethylene Petri dish $\left(120 \times 120 \times 17 \mathrm{~mm}^{3}\right)$. The mixture was then degassed under vacuum until the air bubbles were completely removed. The PDMS film formed after two days at room temperature and was cut into $18 \times 18$ mmsquares with a thickness less than $1 \mathrm{~mm}$. The curing time can be considerably reduced by increasing the temperature (few hours at $70^{\circ} \mathrm{C}$ and about $1 \mathrm{~h}$ at $120^{\circ} \mathrm{C}$ ) [35].

\section{Preparation of PDMS-PVBAC surfaces}

The PDMS films were immersed in an acetone solution containing $20 \mathrm{wt} \%$ of BP for $30 \mathrm{~min}$ to absorb enough BP for the photografting and photopolymerization. The samples were quickly washed with methanol and then placed on a plate to dry in the dark. Then, 50 to $80 \mu 1$ of a methanol solution containing VBAC was applied to the dry samples and covered with a glass slide so that the monomer solution was spread evenly over the surface of the PDMS by capillary force. The PDMS assembly was placed in a UV conveyor (UV Fusion Light Hammer 6), and irradiated with the UV light emitted from a small diameter electrodeless bulb combined with the elliptical reflector microwave-powered lamp (500 watts/inch) at a lamp-PDMS distance of $53 \mathrm{~mm}$. Then, BP-initiated VBAC photopolymerization took place from the PDMS surface. After grafting, the samples were collected by immersion in water to detach from the glass slide and then washed in methanol three times. Samples were washed in methanol overnight with gentle agitation and washed again with methanol the next day before being dried under vacuum to ensure that all unreacted monomer and ungrafted BP or VBAC compounds were removed. Untreated PDMS (control 1), PDMS treated with methanol and UV (control 2) as well as PDMS treated with a monomer solution (65wt\%) without UV exposure 
(control 3) were prepared under the same conditions and they underwent the same washing procedure as the PDMS-PVBAC sample.

\section{Measurements}

${ }^{1} \mathrm{H}$ NMR spectra were recorded on a Bruker $300 \mathrm{MHz}$ spectrometer. The ATR-FTIR spectra were recorded on a Nicolet IS-50 FTIR (Thermo, USA) spectrometer, using the VariGATR accessory (Harrick Scientific, Pleasantville, NY) and the DTGS detector, on three independent samples for each experimental condition, with a wave-number range between 600 and $4000 \mathrm{~cm}^{-1}$. Data were obtained with a spectral resolution of $4 \mathrm{~cm}^{-1}$ per 250 scans.

Static and dynamic water contact angles measurements were performed using a contact angle goniometer "digidrop" (United Kingdom) in air at room temperature on at least three independent samples, using at least 3 droplets by sample.

X-Ray Photoelectron spectroscopy (XPS) analysis was performed using a Thermo Electron Escalab 250 spectrometer, with a monochromatic Al Ka X-ray source $(\mathrm{hn}=1486.6 \mathrm{eV})$ operating at a pressure around $10^{-9}$ mbar. The spectrometer was calibrated using Au4f7/2 at 84.1Ev. The take-off angle was $90^{\circ}$ and the analyzed surface was a $500 \mu \mathrm{m}$ diameter disk. Survey spectra were recorded with a pass energy of $100 \mathrm{eV}$ and a step of $1 \mathrm{eV}$. Spectra were recorded using the Thermo Avantage software and analyzed using CasaXPS software.

The topography of PDMS surfaces before and after modification were analyzed by using a Nanoscope 8 Multimode microscope (Bruker Nano Surfaces, Santa Barbara, CA, USA). Imaging was achieved in the air using the PeakForce ${ }^{\circledR}-\mathrm{QNM}$ mode with a $100 \mu \mathrm{m}$ piezoelectric scanner. A silicon cantilever (RTESPA-300, Bruker) with a spring constant of approximately $40 \mathrm{~N} / \mathrm{m}$ and a silicon tip was used. Images were obtained with a PeakForce tapping frequency of $1 \mathrm{kHz}$ and the auto-amplitude on. AFM imaging was performed at multiple locations (at least 2) on at least two independent samples at two scan sizes: $5 \times 5$ and 20x20 $\mu \mathrm{m}^{2}$. All images are presented in the height mode and are top view images. Flatten \& three points levelling operations were usually done using the Gwyddion AFM software.

\section{Determination of the surface accessible quaternary ammonium density}

Surface quaternary ammonium densities were quantified according to a method described by Tiller et al. [48]. Modified and unmodified PDMS surfaces $\left(1.8 \times 1.8 \mathrm{~cm}^{2}\right)$ were immersed in a solution of fluorescein sodium salt $(1 \%$ in distilled water) for $10 \mathrm{~min}$. Afterwards, the unreacted fluorescein molecules were removed by washing the surface with distilled water. The samples were 
then placed in $3 \mathrm{~mL}$ of a $0.5 \%$ hexadecyltrimethyl ammonium bromide solution to exchange with the bounded fluorescein molecules under ultrasound for $15 \mathrm{~min} .0 .45 \mathrm{~mL}$ of saturated $\mathrm{NaHCO}_{3}$ solution was added after sonication. Then the absorbance of solution was recorded at $501 \mathrm{~nm}$, using a 'Cary bio' UV-visible spectrophotometer (from Varian). The fluorescein concentration was then calculated using a calibration curve.

\section{Antimicrobial activity assay of planktonic bacteria with CFU counting}

The antimicrobial activity towards bacteria in suspension was performed by using a modified ASTM standard: E2149-01 Standard Test Method for Determining the Anti-microbial Activity of Immobilized Antimicrobial Agents Under Dynamic Contact Conditions [49]. Briefly, bacterial species were pre-cultured in $15 \mathrm{~mL}$ of $\mathrm{BHI}$ in a sterile $50 \mathrm{~mL}$ conical tube (Falcon) at $37^{\circ} \mathrm{C}$ under shaking at $140 \mathrm{rpm}$ overnight. Subsequently, the bacteria were harvested by centrifugation $\left(\operatorname{Sigma}^{\circledR} 3-16 \mathrm{KI}\right.$, rotor 19776 , Germany) at $1600 \mathrm{rpm}$ for $15 \mathrm{~min}$ at $20{ }^{\circ} \mathrm{C}$ and resuspended in PBS and diluted to the desired concentration. Modified and unmodified PDMS samples (control) were incubated with $10 \mathrm{ml}$ of bacterial suspension in a $50 \mathrm{ml}$ conical tube at $37^{\circ} \mathrm{C}, 200 \mathrm{rpm}$ for $1 \mathrm{~h}$. The samples were then collected and rinsed with PBS $(1 \mathrm{ml} \times 3$ times $)$. Decimal dilutions of the resulting bacterial suspension were spread on BHI agar plates and incubated at $37{ }^{\circ} \mathrm{C}$ for $24 \mathrm{~h}$ before colony counting. All experiments were performed in triplicate and the experiments were repeated at least three times. The percentage of bacteria killed in suspension by the modified surface was calculated with regards to the number of suspended bacteria in the control (unmodified PDMS).

\section{Antimicrobial activity assay (Live/Dead test)}

A $130 \mu 1$ droplet of $E$. coli or $S$. aureus suspension in distilled water $\left(5.8 \times 10^{8}\right.$ cell $\left./ \mathrm{ml}\right)$ was spread on the modified surfaces $(1.8 \mathrm{~cm} \times 1.8 \mathrm{~cm})$ using a glass slide of the same surface size for $1 \mathrm{~h}$. Then the glass slide was removed and the surface was washed with a stream of distilled water to remove unattached bacteria. After, a $130 \mu 1$ mixture of two fluorescent markers: the SYTO ${ }^{\circledR}$ and the propidium iodide, was deposed and spread on the surface for $15 \mathrm{~min}$. The mixture was diluted before use $\left(20 \mu \mathrm{mol} / 1\right.$ of SYTO $\left.{ }^{\circledR} 9\right)$. Images $(1024 \times 1024$ pixels $)$ of the surfaces were acquired using a Leica TCS SP8 CFS confocal microscope with fixed stature (Leica Microsystems, Nanterre, France) equipped with diodes laser (Coherent, Les Ulis, France) at $488 \mathrm{~nm}$ to excite the SYTO ${ }^{\circledR} 9$ and at 552 $\mathrm{nm}$ to excite Propidium Iodide and a conventional scanner at $400 \mathrm{~Hz}$. Fluorescence emission was detected sequentially by a hybrid detector (Leica Microsystems, Nanterre, France) in photon counting mode with a specific band from 500 to $540 \mathrm{~nm}$ for $\mathrm{SYTO}^{\circledR} 9$ and 580 to $630 \mathrm{~nm}$ for Propidium Iodide. Z-Stack images were acquired using an adapted step-size from Nyquist Criteria. ImageJ (Rasband 
W.S., U.S. National Institutes of Health, Bethesda, Maryland, USA, http://imagej.nih.gov/ij/, 19972020) was used to adjust brightness and contrast and to perform z projections of 3D images (xyz).

\section{Results and discussion}

Study of the photo-initiated polymerization of VBAC from the PDMS surface (preparation of PDMS-PVBAC)
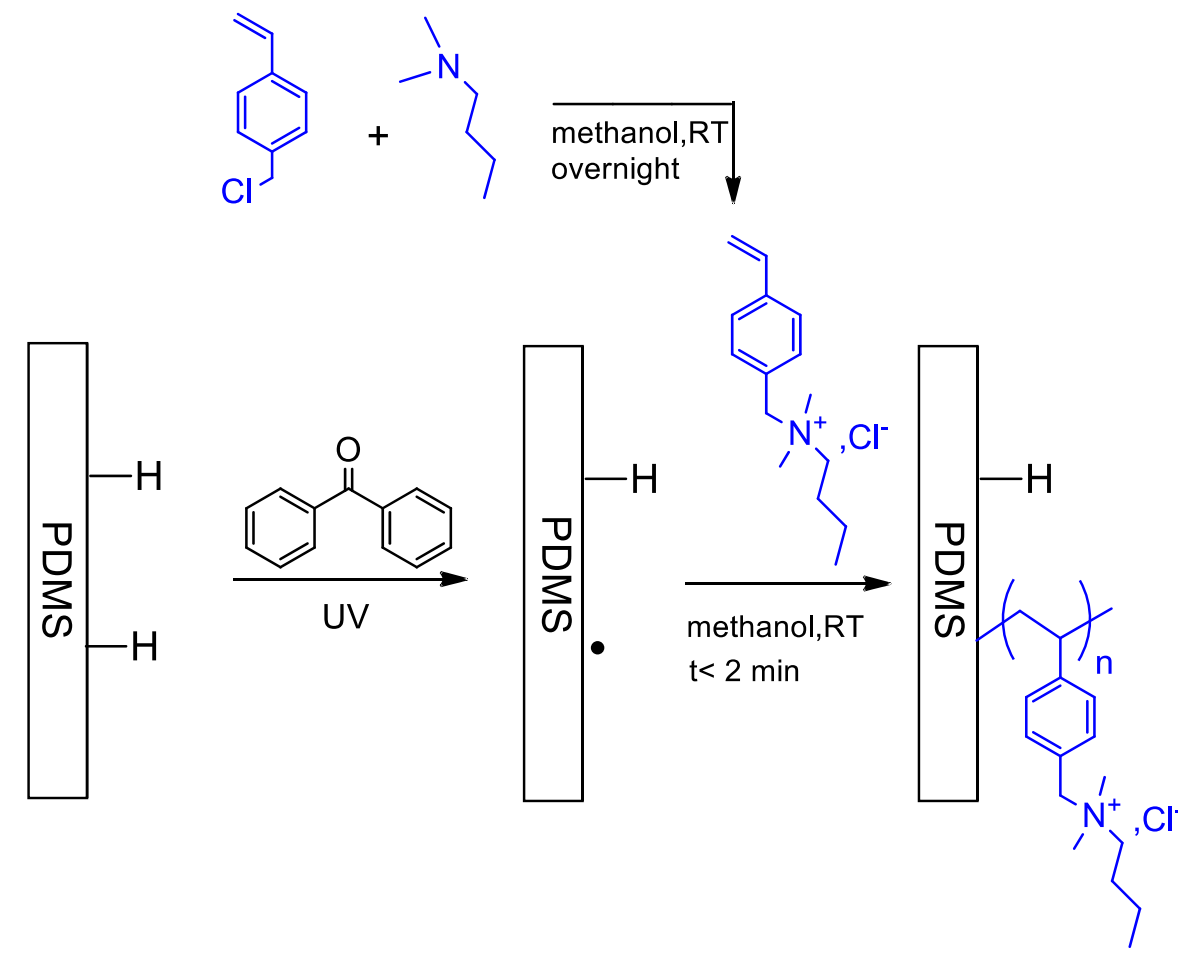

Scheme 1. Synthesis of $N, N$-dimethylbutyl vinylbenzyl ammonium chloride (VBAC) and its photopolymerization from the PDMS surface.

In this work, we propose to prepare poly $(N, N$-dimethylbutyl vinylbenzyl ammonium chloride) grafted PDMS surfaces with high QA density and wettability, through a direct photo-initiated surface polymerization of the corresponding monomer. This 'grafting from' process will be compared to the previously described 'grafting to' process, where this polymer was grafted to the PDMS surface by hydrosilylation in water [35].

We have shown in previous works [35,55] that for poly(N,Ndimethylbutylvinylbenzylammonium chloride) (PVBAC) based homo- and co-polymers, prepared from a poly(vinylbenzyl chloride) (PVBC) of $\mathrm{Mw}=50000 \mathrm{~g} / \mathrm{mol}$, the butyl chain of the ammonium group was sufficiently long to provide an appropriate hydrophilic/hydrophobic balance to the polymer chain, making it water soluble and highly bactericidal. The minimum inhibitory concentration (MIC) of the polymer in water was estimated to be $12 \mathrm{~g} / \mathrm{ml}$ against $E$. coli (Gram-) and $6 \mathrm{~g} / \mathrm{ml}$ against $S$. 
epidermidis $(\mathrm{Gram}+)$. In contrast, for longer chain lengths ( $\mathrm{C} 8$ and longer), the polymer partially or completely loses its solubility in water, so the "grafting on" process cannot be performed in pure water medium and MIC values cannot be determined under appropriate comparative conditions.

Ikeda et al [20] found that the activities of the synthesized polycations were highly dependent on their $\mathrm{Mw}$ and had a bell shape. The polymers were found to be much more active than their corresponding monomers. Effective antibacterial activity was obtained for optimal Mw values ranging from 50000 to $100000 \mathrm{~g} / \mathrm{mol}$. Thus, for $\mathrm{Mw}=24400 \mathrm{~g} / \mathrm{mol}$, poly $(\mathrm{N}, \mathrm{N}-$ dimethylbutyl vinylbenzyl ammonium chloride) exhibited MIC values of 330-660 g/ml against E. coli, and 33-66 against $S$. aureus [47].

In this work, we anticipated that photopolymerization will lead to a grafted polymer with an appropriate molecular weight and/or charge density providing bactericidal properties on the PDMS surface.

The monomer $N, N$-dimethylbutyl vinylbenzyl ammonium chloride was prepared by reaction of benzyl chloride with $N, N$-dimethylbutyl amine in methanol overnight at room temperature. The pure monomer was recovered after crystallization and was soluble in water and alcohols, unlike its precursor, i.e. vinylbenzylchloride. ${ }^{1} \mathrm{H}$ NMR spectrum (supporting information) confirmed the chemical structure through the signals of protons of the carbon-carbon double bonds from 5.39 to $6.79 \mathrm{ppm}$ and the protons of methylene of alkyl and benzyl groups in $\quad \alpha$ position to the ammonium atoms from 2.99 to $4.61 \mathrm{ppm}$, respectively. FTIR analysis (supporting information) confirmed the complete conversion of the chloride group into an ammonium group, through the disappearance of the specific VBC vibration bands, especially the one at $1260 \mathrm{~cm}^{-1}$ related to $\mathrm{C}-\mathrm{H}$ bending vibration in the $\mathrm{CH}_{2} \mathrm{Cl}$ group. One can observe also three new bands at 1498,1463 and $1440 \mathrm{~cm}^{-1}$, corresponding to $\mathrm{C}-\mathrm{H}$ bending vibration in $\mathrm{CH}_{2}$ and $\mathrm{CH}_{3}$ groups, respectively, in the alpha position to $\mathrm{N}^{+}$.

The photopolymerization of the styrene ammonium monomer from the PDMS surface was initiated by benzophenone (Scheme 1) and was studied in several conditions in terms of reaction time (corresponding to the number of UV exposures) and monomer solution concentration. Fully cured Sylgard ${ }^{\circledR} 184$ PDMS films, prepared with the conventional PartA/PartB $=1 / 10$ ratio, were used as model and control. A drop of monomer solution was deposed on the PDMS surface and spread using a thin glass plate. Then, the sample was placed in the UV conveyor with a passage speed of around $6.5 \mathrm{~m} / \mathrm{min}$, which corresponds to about $1.55 \mathrm{~s}$ of UV exposure per passage. 
The polymer grafting densities on the silicone surfaces were monitored by contact angle measurements (Figures 1 and 2, Table 1). Untreated PDMS (control 1), PDMS treated with methanol and UV (control 2) as well as PDMS treated with a monomer solution (65wt\%) without UV exposure (control 3) were used as controls. They exhibited water contact angle values around 108, 99 and $105^{\circ}$, respectively, consistent with the high hydrophobicity of PDMS. First, the effect of the number of UV exposures was studied for two monomers concentration (25 and 50wt\%) (Figure 1). One can observe that for $25 \mathrm{wt} \%$, the value of the contact angle with water decreased slightly from $108^{\circ}$ to around $100^{\circ}$ regardless of the number of passages under UV, suggesting a small change in the surface, which kept its hydrophobic character. On the other hand, for a $50 \mathrm{wt} \%$ monomer solution, the average value of the water contact angle decreased from $101^{\circ}$ to $25^{\circ}$ when the number of passages under UV increased from 10 to 60, suggesting an enhancement in surface coverage. Next, we monitored the impact of monomer concentration on surface modification for $50 \mathrm{UV}$ exposures (Figure 2). The results showed that between 25 and $40 \mathrm{wt} \%$ monomer concentration, the contact angle values were between 100 and $80^{\circ}$, which are close to the values obtained with similar surfaces prepared by the 'grafting to' method [35]. For concentrations above $40 \mathrm{wt} \%$, the contact angle dropped dramatically to $10^{\circ}$ for a concentration of $65 \mathrm{wt} \%$, which is characteristic of a highly hydrophilic surface, suggesting a good degree of surface coverage. Thus, all subsequent studies were performed on PDMS surfaces treated with a $65 \mathrm{wt} \%$ monomer solution after $50 \mathrm{UV}$ runs (Table 1 ).

Dynamic water contact angle measurements were also performed on the optimal surface (Table 1). The advancing angle (AA) is characteristic of the wettability of the hydrophobic part of the surface whereas the receding angle (RA) is ascribed to the hydrophilic part. One can observe that AA, RA and the hysteresis (AA-RA) decreased dramatically, after the polymer was grafted onto the surface, from 116,58 and $57^{\circ}$ (control 1) to 36,12 and $23^{\circ}$ (PDMS-PVBAC), respectively, suggesting once again a good surface coverage. Changes in hysteresis values are commonly ascribed to changes in chemical and/or physical surface heterogeneities. 


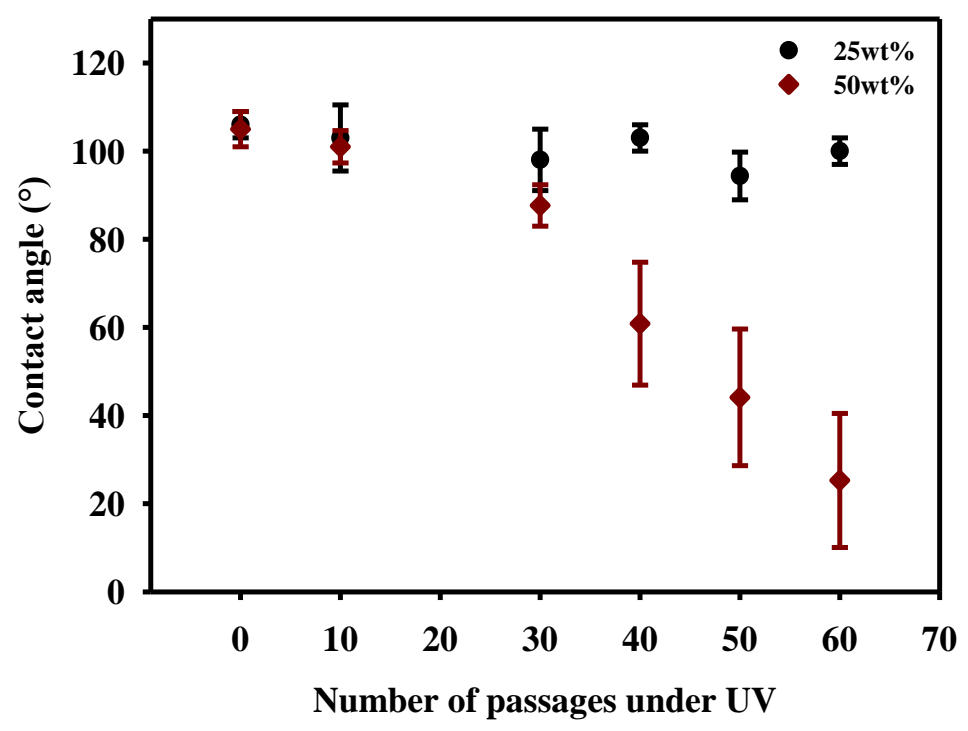

Figure 1. Static water contact angle values of PDMS modified with 25 and $50 \mathrm{wt} \%$ monomer solution with different number of passages under UV.

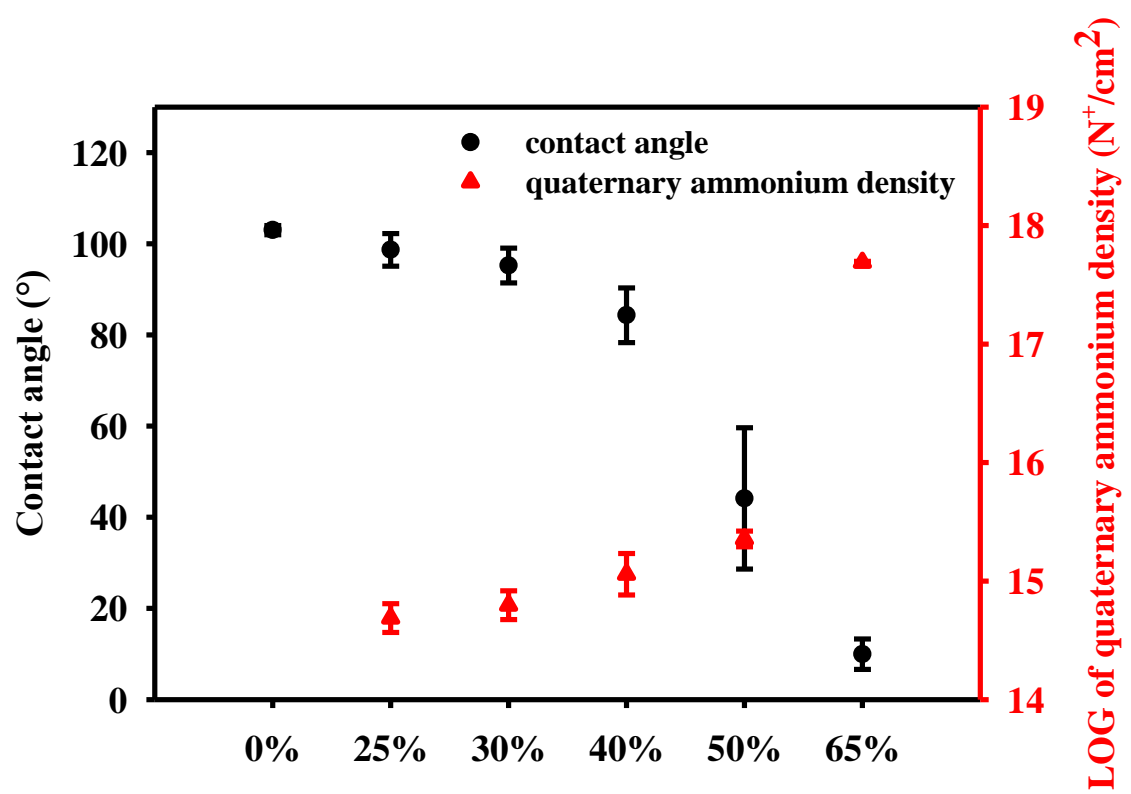

Figure 2. Static water contact angle values and log of quaternary ammonium density of modified PDMS with $25,30,40,50$ and $65 \mathrm{wt} \%$ monomer solution, under $50 \mathrm{UV}$ runs. 
Table 1. Data of water contact angle measurements and surface charge densities on the optimal treated PDMS surface (65wt\% monomer solution under $50 \mathrm{UV}$ runs) and its controls.

\begin{tabular}{|c|c|c|c|c|c|c|c|}
\hline \multirow{2}{*}{ Samples } & \multirow{2}{*}{$\begin{array}{c}\text { Static } \\
\theta_{\text {water }}\left({ }^{\circ}\right)^{\mathrm{a}}\end{array}$} & \multicolumn{3}{|c|}{ Dynamic $\theta_{\text {water }}\left({ }^{\circ}\right)^{\mathrm{a}}$} & \multirow{2}{*}{$\begin{array}{c}\text { QA density } \\
\mathbf{N}^{+} \cdot \mathbf{c m}^{-2}\end{array}$} & \multicolumn{2}{|c|}{$\begin{array}{c}\text { Roughness by } \\
\text { AFM }^{\mathrm{b}}(\mathrm{nm})\end{array}$} \\
\hline & & $\mathbf{A A}$ & RA & Hyst $\left(^{\circ}\right)$ & & $\mathbf{R a}$ & RMS \\
\hline $\begin{array}{c}\text { PDMS } \\
\text { (control 1) }\end{array}$ & $108 \pm 2$ & $116 \pm 3$ & $58 \pm 4$ & $57 \pm 2$ & $\mathrm{ND}^{\mathrm{c}}$ & $0.9 \pm 0.1$ & $1.2 \pm 0.2$ \\
\hline $\begin{array}{l}\text { PDMS-MeOH } \\
\text { (control 2) }\end{array}$ & $99 \pm 7$ & $121 \pm 8$ & $45 \pm 10$ & $77 \pm 2$ & $\mathrm{ND}^{\mathrm{c}}$ & l & l \\
\hline $\begin{array}{l}\text { PDMS-VBAC } \\
\text { without UV } \\
\text { (control 3) }\end{array}$ & $105 \pm 2$ & $118 \pm 2$ & $54 \pm 1$ & $65 \pm 2$ & $\mathrm{ND}^{\mathrm{c}}$ & / & / \\
\hline PDMS-PVBAC & $10 \pm 3$ & $36 \pm 2$ & $12 \pm 5$ & $23 \pm 4$ & $(4.8 \pm 0.1) \times 10^{17}$ & $5.5 \pm 0.6$ & $6.7 \pm 0.6$ \\
\hline
\end{tabular}

Assessment of surface charge density is very useful to predict the contact killing efficiency of quaternary ammonium surfaces [50-57]. It has been shown that the surface must exhibit a charge density above $10^{14} \mathrm{~N}^{+} . \mathrm{cm}^{-2}$ to kill efficiently E. coli and S. epidermidis [57].

The values of charge density of cationic PDMS surfaces prepared with different monomer concentrations at $50 \mathrm{UV}$ passages are depicted in Figure 2 and Table 1. One can observe that all the values were above $10^{14} \mathrm{~N}^{+} . \mathrm{cm}^{-2}$, suggesting a high potential for bacterial killing. Furthermore, these values increased with the hydrophilicity of the surface, i.e. with decreasing values of the contact angle with water, reaching a very high value of $4.8 \times 10^{17} \mathrm{~N}^{+} . \mathrm{cm}^{-2}$ for the optimal surface. On the other hand, cationic PDMS surfaces with water contact angle above $80^{\circ}$ exhibited charge densities ranging from $5 \times 10^{14}$ to $5 \times 10^{15} \mathrm{~N}^{+} . \mathrm{cm}^{-2}$, i.e. close to those of analogous surfaces prepared by the "grafting to" approach [35].

Moreover, the proposed "grafting from" photo process has many advantages over the "grafting to" hydrosilylation process [35]:

- The synthesis of the QA monomer (grafting from) is faster and easier than the synthesis of the corresponding copolymer (grafting to).

- The photografting process is very fast than the hydosilylation process.

- The photografting process provides an effective surface modification after full crosslinking of PDMS compared to the hydosilylation process, with respectively: 
Charge density values around $10^{17} \mathrm{~N}^{+} / \mathrm{cm}^{2}$ vs. $10^{14} \mathrm{~N}^{+} / \mathrm{cm}^{2}$; WCA of $10^{\circ}$ vs. $102^{\circ}$; approximately $100 \%$ killing of bacteria in surface and in suspension (up to a challenge of $10^{6}$ $\mathrm{CFU} / \mathrm{cm}^{2}$ ) vs. $96 \%$ of killing efficiency, only on the surface. In addition, the enhancement of the surface grafting by hydrosilylation, using partially cured PDMS or by changing the A/B ration of the Sylgard 184 components, led to maximal values of charge densities of about $10^{5}$ $\mathrm{N}^{+} / \mathrm{cm}^{2}$, WCA of about $88^{\circ}$ and bacterial killing of about $100 \%$, only on the surface, which is still lower than 'grafting from' values.

\section{Surface characterization by AFM}

AFM analyses revealed the structural and topographical changes on the PDMS surfaces after photochemical grafting and polymerization of the cationic monomer (Figure 3 and supplementary data). The roughness values of these PDMS surfaces are depicted in Table 1. The native PDMS surface was very smooth with an arithmetic roughness of about $0.9 \pm 0.1 \mathrm{~nm}$ and a mean square roughness of about $1.2 \pm 0.2 \mathrm{~nm}$ (Figure 3-A). The quaternary ammonium PDMS surface exhibited an increased roughness values of about $5.5 \pm 0.6 \mathrm{~nm}$ and $6.7 \pm 0.6 \mathrm{~nm}$, respectively (Figure 3-B). One can observe also that the surface coverage increased with the concentration of the starting monomer solution, which led to the increase of the surface hydrophilicity and the decrease of the average roughness values and/or their standard deviations (supplementary data). In addition, AFM images suggest an island-like growth of polymer chains in all three spatial directions. In fact, the polymerization reactions are initiated only from the surface sites where BP is present. Moreover, the start times of the initiation and propagation steps of the free radical polymerization can vary from site to site, depending on the accessibility of the BP, causing a gradient of grafted polymer leading to chemical (coverage) and physical (roughness) surface heterogeneities. The white spots in the AFM images can be ascribed to polymer aggerates on the surface. The spots in the untreated surface are rarely present, which can be ascribed to slight surface contamination by dust or other particles in the atmosphere or during manipulation with the clamp. 


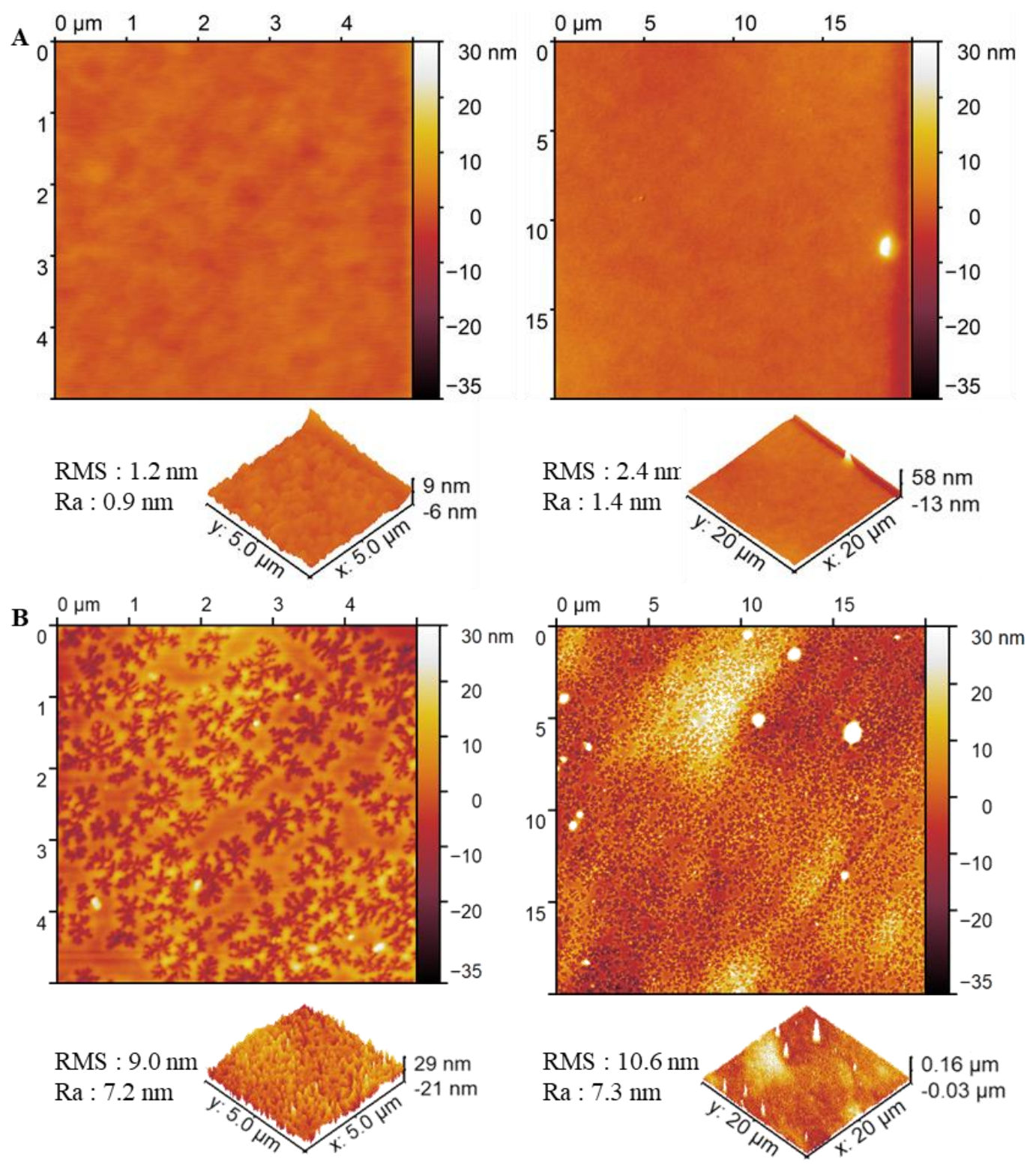

Figure 3. AFM images of (A) PDMS surface (control 1) and (B) PDMS-PVBAC surface. 


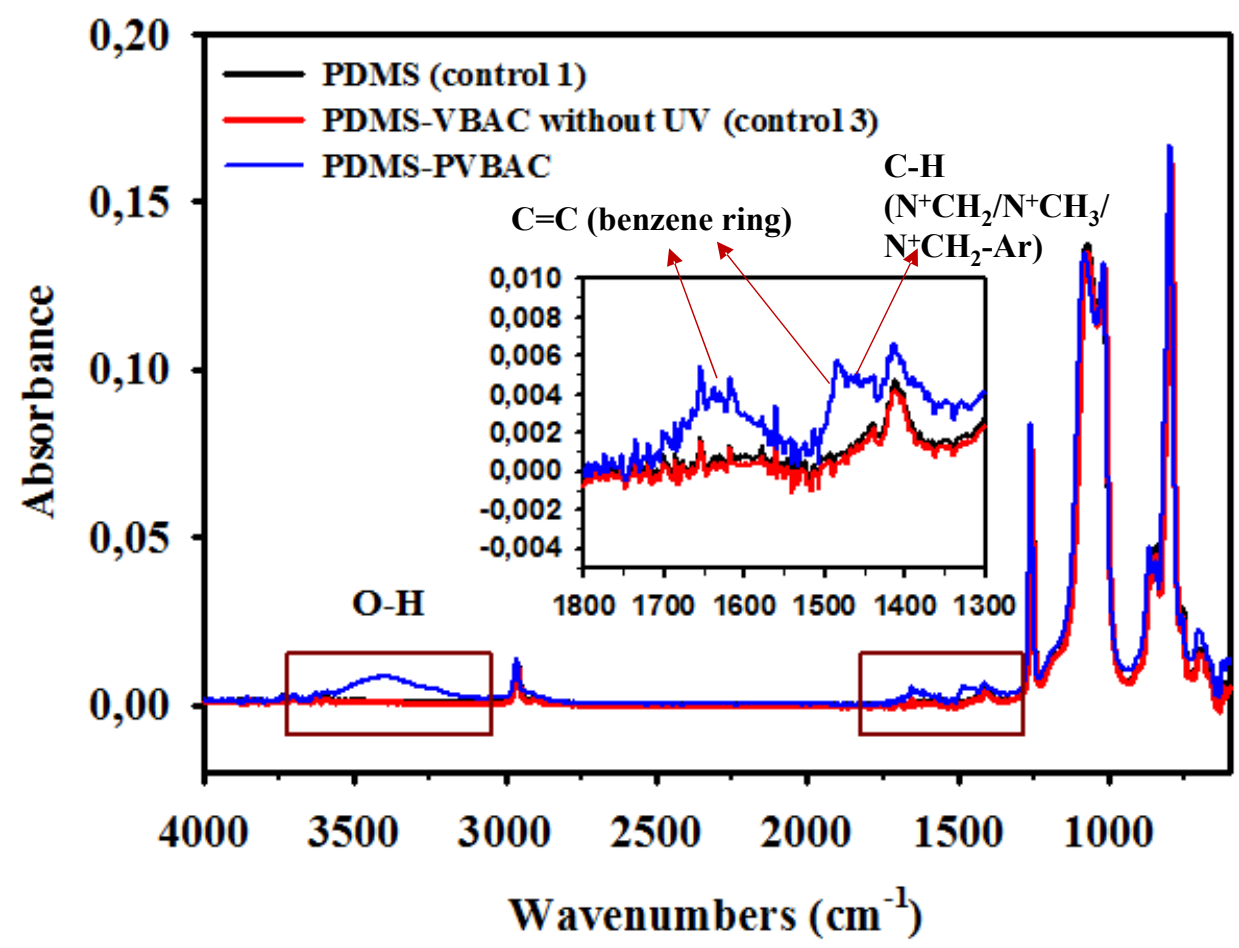

Figure 4. FTIR- ATR spectra of (from the top to bottom): PDMS (control 1), PDMS-VBAC without UV (control 3) and PDMS-PVBAC.

FTIR-ATR analysis (Figure 4) of the prepared cationic surface, compared to its controls, showed supplementary bands between 1440 and $1700 \mathrm{~cm}^{-1}$ ascribed to the benzyl ring of the grafted cationic polymer and also to the $\mathrm{C}-\mathrm{H}$ bending vibration in $\mathrm{N}^{+}-\mathrm{CH}_{2}-\mathrm{Ar}, \mathrm{N}^{+}-\mathrm{CH}_{2}$ and $\mathrm{N}^{+}-\mathrm{CH}_{3}(1440$ and $\left.1498 \mathrm{~cm}^{-1}\right)$. A slight contribution of the butyl chain was also observed in the region of 2800 $3100 \mathrm{~cm}^{-1}$ (supplementary information). One can observe also a band at $3300 \mathrm{~cm}^{-1}$ arising from moisture, due to the hygroscopic character of the cationic surface. The FTIR spectra of controls 1 and 3 were identical, suggesting that UV treatment was indispensable for the grafting reaction to occur and that the washing with methanol to remove the monomer was effective.

The atomic compositions of PDMS and PDMS-PVBAC surfaces were obtained by XPS and the results are presented in the Table 2. XPS analysis of the PDMS surface showed clearly the presence of carbon, oxygen and silicon with a composition close to that expected. The slight enrichment observed for $\mathrm{O}$ and $\mathrm{Si}$ could be explained by the fact that Sylgard 184 does not have a pure PDMS chemical structure, it contains hydro-siloxane (Si-H) groups in residual amount after curing, which may contribute to the observed decrease in carbon content. The presence of residual $\mathrm{SiO}_{2}$ precursor is also a likely reason. PDMS-PVBAC surface also revealed the presence of $\mathrm{N}(1.2 \%)$ 
and $\mathrm{Cl}(1.2 \%)$ at a ratio of 1 , associated with a strong enrichment of carbon, suggesting that the photo-grafting reaction was successful. It is noteworthy that the $\mathrm{C} / \mathrm{N}$ and $\mathrm{C} / \mathrm{Cl}$ ratios are equal to 15 in the VBAC and PVBAC, which explain the low values of the $\mathrm{N}$ and $\mathrm{Cl}$ percentages.

Table 2. XPS elemental analysis of the optimal modified PDMS surface and its unmodified PDMS control.

\begin{tabular}{ccccccccccc}
\hline & $\mathbf{C 1 s}$ & $\mathbf{O 1 s}$ & $\mathbf{S i 2 p}$ & $\mathbf{N 1 s}$ & $\mathbf{C l 2 p}$ & $\mathbf{C} / \mathbf{O}$ & $\mathbf{C} / \mathbf{S i}$ & $\mathbf{O} / \mathbf{S i}$ & $\mathbf{N} / \mathbf{C l}$ & $\mathbf{O} / \mathbf{C l}$ \\
\hline PDMS & 43.4 & 30.2 & 26.4 & -- & -- & 1.4 & 1.6 & 1.1 & -- & -- \\
$\begin{array}{c}\text { PDMS- } \\
\text { PVBAC }\end{array}$ & 71.7 & 14.7 & 11.2 & 1.2 & 1.2 & 4.9 & 6.4 & 1.3 & 1.0 & 12.3 \\
\hline
\end{tabular}

A way to represent the grafting density is to calculate an average thickness of the organic layer formed at the surface of the PDMS substrate. Thus, using a model including the coverage rate of the grafter layer on the PDMS surface, it is possible to use the following set of equations to determine an average thickness of island [58]:

$I_{C l}=\gamma K n_{C l}^{\text {layer }} \sigma_{C l} \lambda_{C l}^{\text {layer }} T_{C l}\left(1-\exp \frac{-d}{\lambda_{C l}^{\text {layer }}}\right)$

$I_{S i}=\gamma K n_{S i}^{P D M S} \sigma_{S i} \lambda_{S i}^{P D M S} T_{S i}\left(\exp \frac{-d}{\lambda_{S i}^{\text {layer }}}\right)+(1-\gamma) K n_{S i}^{P D M S} \sigma_{S i} \lambda_{S i}^{P D M S} T_{S i}(2)$

With $\gamma$ is the coverage rate, I is the intensity of photoelectrons emitted by the element $\mathrm{X}, \mathrm{K}$ a constant characteristic of the spectrometer, $\sigma$ the photoionization cross section of the core level of the considered element, $\lambda$ the inelastic mean free path of the photoelectrons emitted by the core level of the considered element, $\mathrm{n}$ is the bulk concentration, $\mathrm{T}$ the transmission function for the electrons emitted by the core level of the element and $d$ the thickness of the organic layer (values are given in the supplementary data).

Thus, assuming that the coverage rate is between 50 and $60 \%$, as suggested by the AFM images, solving these equations resulted in an equivalent average grafted layer thickness of about $1.2-1.35 \mathrm{~nm}$. 


\section{Assessment of the surface bactericidal properties}

The bactericidal properties of the PDMS cationic surfaces against E. coli (Gram-), S. aureus $(\mathrm{Gram}+)$ and $S$. epidermidis (Gram+) were studied by confocal fluorescent microscopy through the Live and Dead assay. Figure 5 displays examples of Live and Dead fluorescent images performed on modified and unmodified PDMS surfaces. Bacteria were spread onto the surfaces and then stained with a mixture of fluorescent probes that stain bacteria with damaged membrane red and those with intact membrane green. For the cationic PDMS surfaces, only red bacteria were observed confirming their contact killing property.

Moreover, the adhesion of E. coli (Figure 5A) and S. epidermidis (Figure 5B) seems to be principally governed by electrostatic forces since the bacteria have an overall negative charge and their attachment onto cationic surfaces is very dense (around $10^{6} \mathrm{cell} / \mathrm{cm}^{2}$ ) and very fast comparing to the unmodified PDMS surface (control), which did not display any significative bacteria attachment after $1 \mathrm{~h}$ of contact. This result is consistent with the literature data in terms of the dependence of the surface bacterial density and the bactericidal efficiency on the surface charge density. Similar surfaces prepared by the "grafting to" method exhibited 98 to $100 \%$ killing efficiency after 1 h of contact with E. coli and S. epidermidis suspensions. They also displayed a density of surface attached bacteria between $10^{5}$ and $10^{6} \mathrm{cell} / \mathrm{cm}^{2}$, while the charge densities varied from $2 \times 10^{14}$ to $1.2 \times 10^{15} \mathrm{~N}^{+} . \mathrm{cm}^{-2}$ [35]. In contrast, S. aureus exhibited surprisingly high affinity and attachment on the unmodified PDMS surface (around $10^{6} \mathrm{cell} / \mathrm{cm}^{2}$ ), where they keep their viability, suggesting that this attachment is independent on the electrostatic phenomenon. On the other hand, after $1 \mathrm{~h}$ of contact with the cationic PDMS surface, the integrity of the bacterial membrane was also perturbed and quasionly red bacteria were observed (Figure 5C). 

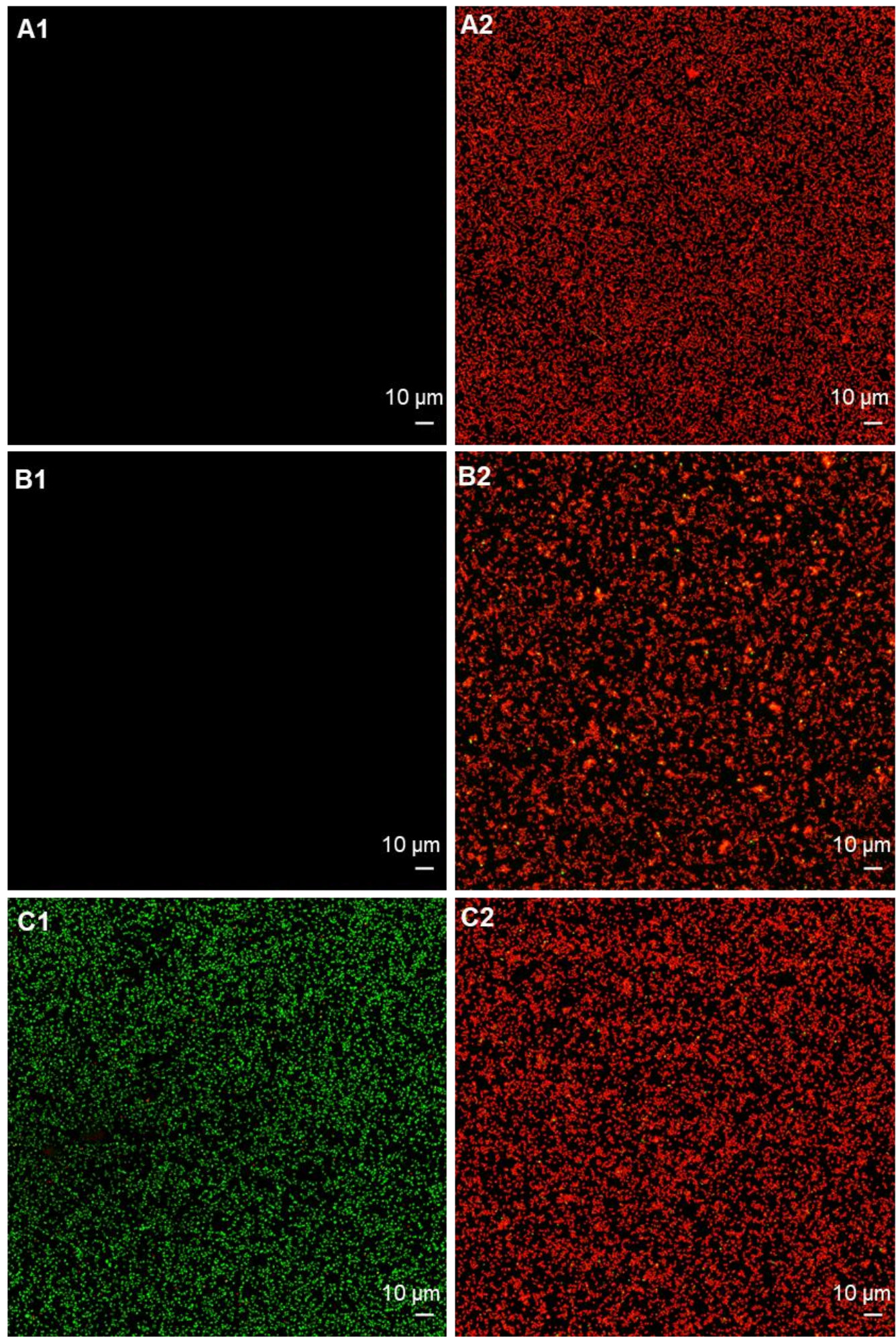

Figure 5. Fluorescence microscopy images of sessile bacteria cells stained with a marker of viability and deposited on surfaces of modified and unmodified PDMS surfaces: (A1) E. coli on unmodified PDMS surface (control), (A2) E. coli on cationic PDMS-PVBAC surface, (B1) S. epidermidis on unmodified PDMS surface (control), (B2) S. epidermidis on cationic PDMS-PVBAC surface, (C1) S. aureus on unmodified PDMS surface (control), (C2) S. aureus on cationic PDMS-PVBAC surface. Bacteria become non-viable after less than $1 \mathrm{~h}$ of contact with the charged surface. 
The bacterial killing capacity of the optimal cationic surface against $E$. coli and $S$. aureus in suspension was also studied using a modified ASTM standard: E2149-01. The long-term bactericidal activity of a cationic surface depends on the concentration of bacteria exposed to it. To study this parameter, the surface was challenged with different bacterial concentrations in suspension during $1 \mathrm{~h}$ of contact, then the number of viable cells in suspension was counted by bacterial enumeration on BHI agar plates (Figure 6). The cationic surfaces exhibited a high bactericidal activity with a quantitative eradication of bacteria in suspension. One can observe that a drop off in the percentage of bacterial killing occurs at around $10^{8}$ cells $/ \mathrm{cm}^{2}$, which corresponds to the limit of coverage of the surface by bacteria. Indeed, it has been shown that the bactericidal power of the cationic surface increases with its charge density. Above $5 \times 10^{15}$ charges $/ \mathrm{cm}^{2}$ the surface becomes capable of killing at least one monolayer of $E$. coli cells, before passing through fouling and losing its bioactivity. Since the bacteria cell covers about $1 \mu \mathrm{m}^{2}$ of the surface, $1 \mathrm{~cm}^{2}$ should be completely covered with around $10^{8}$ cells if they are perfectly arrayed [49]. Furthermore, under the shaking conditions of this test, all suspended bacteria must be in contact with the surface during the hour of testing. Bacteria will attach firmly to the surface but can potentially be driven off by surface shear forces. When the number of bacteria reaches or exceeds the number of bacteria saturating the surface, the unoccupied spaces on the surface are reduced and some bacteria escape death [49]. Thus, the bactericidal effect of the QA surface in bacterial suspension is its ability to bind bacteria, to kill them and keep them on it.

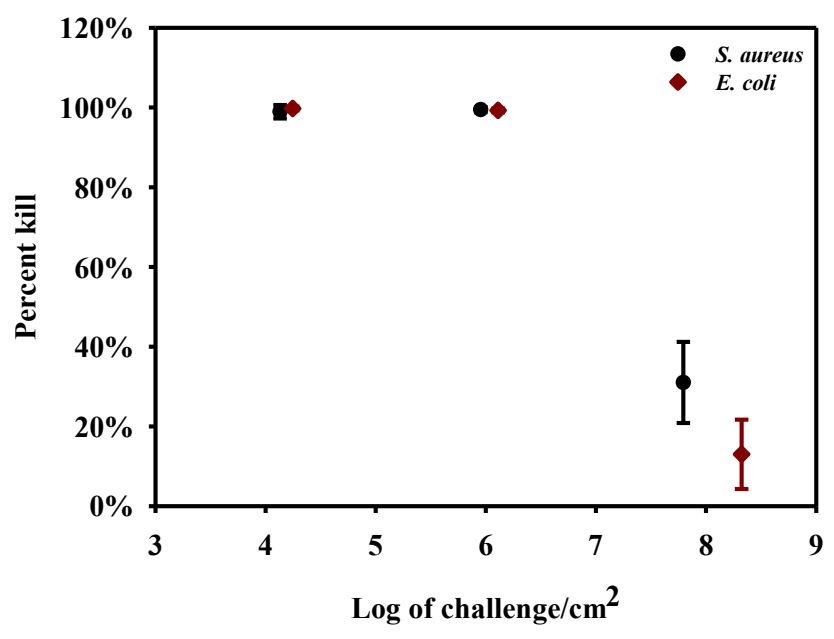

Figure 6. Determination of the bacterial killing capacity for the optimal cationic PDMS surface (PDMSPVBAC) with a charge density of $(4.8 \pm 0.1) \times 10^{17} \mathrm{~N}^{+} . \mathrm{cm}^{-2}$. Samples were incubated with increasing challenges of $E$. coli. The survivors were counted and compared with a control. 
One can observe also is that QA-PDMS surfaces prepared by the photografting process showed higher capacity in terms of bacterial killing capacity compared to analogues prepared by the hydrosilylation process. Indeed, when hydrosilylation was performed after PDMS curing, 96\% of killing efficiency was obtained on the surface. The enhancement of the surface grafting by hydrosilylation, using partially cured PDMS or by changing the A/B ration of the Sylgard 184 components led to about $100 \%$ of bacterial killing capacity on the surface, which was not, however, measured in suspension [35]. On the other hand, on the base of these results and the reported dependance of killing capacity on charge density [49], we can suggest that the longevity of the QA-PDMS surfaces prepared by the photografting process is higher, since it will take more time to these surfaces to be exposed to bacterial concentration that passivate it.

Some studies have evidenced that, in solution, quaternary ammonium may be cytotoxic, depending on concentration, time exposure and chemical structure [59-61]. However, the biocompatibility of cationic surfaces needs further investigations to determine whether we would use them for medical device applications [62]. In a previous work [35], we have demonstrated that plasmatic proteins, because they are electrically charged, are adsorbed on QA surfaces, which quantitatively lost their bactericidal efficiency after 24 hours of contact with them. Consequently, this result suggested to avoid their use in blood contact applications. On the other hand, currently, we can suggest to use this kind of surface in all silicone devices that are not in contact with blood, such as the external surfaces of catheter chambers and extracorporeal equipment.

\section{Conclusion}

Bactericidal cationic PDMS surfaces were successfully prepared by photo-induced polymerization of a styrene ammonium monomer from the surface in the presence of benzophenone. The reaction was optimized in terms of duration and monomer concentration. By varying these two parameters, surface charge densities and contact angle with water (hydrophilicity) can be fine-tuned from about $10^{14}$ to $10^{17} \mathrm{~N}^{+} . \mathrm{cm}^{-2}$ and from about 100 to $10^{\circ}$, respectively. The Live and Dead test by fluorescence microscopy revealed an efficient contact killing of the optimal surface against $E$. coli, S. aureus and S. epidermidis. Bacterial enumeration showed that this surface is capable of killing bacteria in suspension up to a concentration greater than $10^{6} \mathrm{CFU} / \mathrm{mL}$. Finally, the prepared QA-PDMS surfaces revealed higher performances comparing to the analogues prepared by the hydrosilylation process. 


\section{Acknowledgments}

Authors thanks the INSA ROUEN NORMANDIE and the China Scholarship Council (CSC) for the financial supports. This manuscript is a tribute to the 50-year anniversary of the French Polymer Group (Groupe Français des Polymères - GFP).

\section{Data availability statement}

The raw/processed data required to reproduce these findings cannot be shared at this time due to technical or time limitations. 


\section{References}

[1] H. Gu, S. W. Lee, J. Carnicelli, T. Zhang, and D. Ren, "Magnetically driven active topography for longterm biofilm control," Nat. Commun., vol. 11, no. 1, pp. 1-11, 2020.

[2] M. Salwiczek et al., "Emerging rules for effective antimicrobial coatings," Trends Biotechnol., vol. 32, no. 2, pp. 82-90, 2014.

[3] Y. Lou, P. Thebault, F. Burel, and N. Kebir, "Antibacterial properties of metal and PDMS surfaces under weak electric fields," Surf. Coatings Technol., p. 125912, 2020.

[4] J. Hasan and K. Chatterjee, "Recent advances in engineering topography mediated antibacterial surfaces," Nanoscale, vol. 7, no. 38, pp. 15568-15575, 2015.

[5] D. Alves and M. Olívia Pereira, "Mini-review: Antimicrobial peptides and enzymes as promising candidates to functionalize biomaterial surfaces," Biofouling, vol. 30, no. 4, pp. 483-499, Apr. 2014.

[6] Z. Li, S. Wang, X. Yang, H. Liu, Y. Shan, X. Xu, S. Shang, Z. Song. Antimicrobial and antifouling coating constructed using rosin acid-based quaternary ammonium salt and $\mathrm{N}$-vinylpyrrolidone via RAFT polymerization. Appl. Surf. Sci., vol. 530, pp. 147193, 2020.

[7] B.-L Wang, J.-L Wang, D.-D Li, K.-F Ren, J. Ji. Chitosan/poly (vinyl pyrollidone) coatings improve the antibacterial properties of poly(ethylene terephthalate). Appl. Surf. Sci., vol. 258, no. 20, pp. 78017808C, 2012.

[8] M. Lu, S. Yu, Z. Wang, Q. Xin, T. Sun, X. Chen, Z. Liu, X. Chen, J. Weng, J. Li, Zwitterionic choline phosphate functionalized chitosan with antibacterial property and superior water solubility, Eur. Polym. J., vol. 134, pp. 109821, 2020.

[9] P. Ayaz, B. Xu, X. Zhang, J. Wang, D. Yu, J. Wu. A pH and hyaluronidase dual-responsive multilayerbased drug delivery system for resisting bacterial infection. Appl. Surf. Sci., vol. 527, pp. 146806, 2020.

[10] J. Muller, A. C. Quesada, C. González-Martínez, A. Chiralt, Antimicrobial properties and release of cinnamaldehyde in bilayer films based on polylactic acid (PLA) and starch, Eur. Polym. J., vol. 96, pp. 316-325, 2017.

[11] M. Akia, C. Rodriguez, L. Materon, R. Gilkerson, K. Lozano, Antibacterial activity of polymeric nanofiber membranes impregnated with Texas sour orange juice, Eur. Polym. J., vol. 115, pp. 1-5, 2019.

[12] R. Kaur and S. Liu, "Antibacterial surface design - Contact kill," Prog. Surf. Sci., vol. 91, no. 3, pp. 136153, 2016.

[13] J. Foksowicz-Flaczyk, J. Walentowska, M. Przybylak, and H. Maciejewski, "Multifunctional durable properties of textile materials modified by biocidal agents in the sol-gel process," Surf. Coatings Technol., vol. 304, pp. 160-166, 2016.

[14] A. C. Rios et al., "Alternatives to overcoming bacterial resistances: state-of-the-art," Microbiol. Res., vol. 191, pp. 51-80, 2016.

[15] S. Farah, "Antimicrobial Quaternary Ammonium Polymers for Biomedical Applications," Antimicrob. Mater. Biomed. Appl., vol. 5, p. 277, 2019.

[16] J. Yan, L. Zheng, K. Hu, L. Li, C. Li, L. Zhu, H. Wang, Y. Xiao, S. Wu, J. Liu, B. Zhang, F. Zhang, "Cationic polyesters with antibacterial properties: Facile and controllable synthesis and antibacterial study," Eur. Polym. J., vol. 110, pp. 41-48, 2019. 
[17] J. Velazco-de-la-Garza, L. Avérous, G. de Jesús Sosa-Santillán, E. Pollet, A. Zugasti-Cruz, C. A. SierraRivera, N. V. Pérez-Aguilar, E. Oyervides-Muñoz, Biological properties of novel polysuccinimide derivatives synthesized via quaternary ammonium grafting, Eur. Polym. J., vol. 131, pp. 109705, 2020.

[18] A. Palantoken, M. S. Yilmaz, N. A. Unubol, E. Yenigul, S. Pişkin, T. Eren, Synthesis and characterization of a ROMP-based polycationic antimicrobial hydrogel, Eur. Polym. J., vol. 112, pp. 365-375, 2019.

[19] B. Dizman, M. O. Elasri, and L. J. Mathias, "Synthesis and antimicrobial activities of new water-soluble bis-quaternary ammonium methacrylate polymers," J. Appl. Polym. Sci., vol. 94, no. 2, pp. 635-642, 2004.

[20] T. Ikeda, H. Hirayama, H. Yamaguchi, S. Tazuke, M. Watanabe, Polycationic biocides with pendant active groups: molecular weight dependence of antibacterial activity. Antimicrob Agents Chemother., vol. 30, pp. 132-136, 1986.

[21] J. Guo et al., "Antibacterial activity of cationic polymers: side-chain or main-chain type?," Polym. Chem., vol. 9, no. 37, pp. 4611-4616, 2018.

[22] T. Ikeda, H. Hirayama, K. Suzuki, H. Yamaguchi, and S. Tazuke, "Biologically active polycations, 6. Polymeric pyridinium salts with well-defined main chain structure," Die Makromol. Chemie, vol. 187, no. 2, pp. 333-340, 1986.

[23] A. B. Swanson, "Silicone Rubber Implants for Replacement of Arthritic or Destroyed Joints in the Hand," Surg. Clin. North Am., vol. 48, no. 5, pp. 1113-1127, 1968.

[24] M. Bračič, O. Sauperl, S. Strnad, I. Kosalec, O. Plohl, L. F. Zemljič. Surface modification of silicone with colloidal polysaccharides formulations for the development of antimicrobial urethral catheters. Appl. Surf. Sci., vol. 463, no. 1 , pp. 889-899, 2019.

[25] A. Colas and J. Curtis, "Silicone biomaterials: history and chemistry," Biomater. Sci. an Introd. to Mater. Med., vol. 2, pp. 80-85, 2004.

[26] A. U. Daniels, "Silicone breast implant materials," Swiss Med. Wkly., vol. 142, no. JULY, 2012.

[27] K. W. Dunn, P. N. Hall, and C. T. K. Khoo, "Breast implant materials: sense and safety," Br. J. Plast. Surg., vol. 45, no. 4, pp. 315-321, 1992.

[28] A. Colas, "Silicones: preparation, properties and performance," Dow Corning, Life Sci., 2005.

[29] J. R. Henstock, L. T. Canham, and S. I. Anderson, "Silicon: the evolution of its use in biomaterials," Acta Biomater., vol. 11, pp. 17-26, 2015.

[30] J. Winiecka-Krusnell and E. Linder, "Bacterial infections of free-living amoebae," Res. Microbiol., vol. 152, no. 7, pp. 613-619, 2001.

[31] Q. Gao et al., "Rationally designed dual functional block copolymers for bottlebrush-like coatings: In vitro and in vivo antimicrobial, antibiofilm, and antifouling properties," Acta Biomater., vol. 51, pp. 112-124, 2017.

[32] A. I. Doulgeraki, P. Di Ciccio, A. lanieri, and G. J. E. Nychas, "Methicillin-resistant food-related Staphylococcus aureus: a review of current knowledge and biofilm formation for future studies and applications," Res. Microbiol., vol. 168, no. 1, pp. 1-15, 2017.

[33] C. Donzel et al., "Hydrophilic poly (dimethylsiloxane) stamps for microcontact printing," Adv. Mater., vol. 13, no. 15, pp. 1164-1167, 2001. 
[34] A. Oláh, H. Hillborg, and G. J. Vancso, "Hydrophobic recovery of UV/ozone treated poly (dimethylsiloxane): adhesion studies by contact mechanics and mechanism of surface modification" Appl. Surf. Sci., vol. 239, no. 3-4, pp. 410-423, 2005.

[35] N. Kébir, I. Kriegel, M. Estève, and V. Semetey, "Preparation of bactericidal cationic PDMS surfaces using a facile and efficient approach," Appl. Surf. Sci., vol. 360, pp. 866-874, 2016.

[36] W. Mussard, N. Kebir, I. Kriegel, M. Estève, and V. Semetey, "Facile and efficient control of bioadhesion on poly(dimethylsiloxane) by using a biomimetic approach," Angew. Chemie, vol. 123, no. 46, pp. 11063-11066, 2011.

[37] D.-J. Guo, H.-M. Han, S.-J. Xiao, and Z.-D. Dai, "Surface-hydrophilic and protein-resistant silicone elastomers prepared by hydrosilylation of vinyl poly(ethylene glycol) on hydrosilanes-poly (dimethylsiloxane) surfaces," Colloids Surfaces A Physicochem. Eng. Asp., vol. 308, no. 1-3, pp. 129135, 2007.

[38] Y. Wu, Y. Huang, and H. Ma, "A facile method for permanent and functional surface modification of poly(dimethylsiloxane)," J. Am. Chem. Soc., vol. 129, no. 23, pp. 7226-7227, 2007.

[39] H. Chen, Y. Chen, H. Sheardown, and M. A. Brook, "Immobilization of heparin on a silicone surface through a heterobifunctional PEG spacer," Biomaterials, vol. 26, no. 35, pp. 7418-7424, 2005.

[40] H. Chen, Z. Zhang, Y. Chen, M. A. Brook, and H. Sheardown, "Protein repellant silicone surfaces by covalent immobilization of poly(ethylene oxide)," Biomaterials, vol. 26, no. 15, pp. 2391-2399, 2005.

[41] Y. Wang, H.-H. Lai, M. Bachman, C. E. Sims, G. P. Li, and N. L. Allbritton, "Covalent micropatterning of poly(dimethylsiloxane) by photografting through a mask," Anal. Chem., vol. 77, no. 23, pp. 7539-7546, 2005.

[42] S. Sugiura, J. Edahiro, K. Sumaru, and T. Kanamori, "Surface modification of polydimethylsiloxane with photo-grafted poly (ethylene glycol) for micropatterned protein adsorption and cell adhesion," Colloids Surfaces B Biointerfaces, vol. 63, no. 2, pp. 301-305, 2008.

[43] B. L. Leigh, E. Cheng, L. Xu, A. Derk, M. R. Hansen, and C. A. Guymon, "Antifouling photograftable zwitterionic coatings on PDMS substrates," Langmuir, vol. 35, no. 5, pp. 1100-1110, 2018.

[44] Y. Jiao, L. Niu, S. Ma, J. Li, F. R. Tay, and J. Chen, "Quaternary ammonium-based biomedical materials: State-of-the-art, toxicological aspects and antimicrobial resistance," Prog. Polym. Sci., vol. 71, pp. 5390, 2017.

[45] T. Zhou et al., "Surface functionalization of biomaterials by radical polymerization," Prog. Mater. Sci., vol. 83, pp. 191-235, 2016.

[46] Q. Xu, Z. Zheng, B. Wang, H. Mao, and F. Yan, "Zinc Ion Coordinated Poly(Ionic Liquid) Antimicrobial Membranes for Wound Healing," ACS Appl. Mater. Interfaces, vol. 9, no. 17, pp. 14656-14664, 2017.

[47] T. Ikeda and S. Tazuke, "Synthesis and antimicrobial activity of poly (trialkylvinylbenzylammonium chloride ) s," Makromol. Chemie Macromol. Chem. physicis, vol. 185(5), pp. 869-876, 1984.

[48] J.C. Tiller, C.J. Liao, K. Lewis, A.M. Klibanov, Designing surface that kill bacteria on contact. Proc. Natl. Acad. Sci. USA., vol. 98, pp. 5981-5985, 2001.

[49] H. Murata, R. R. Koepsel, K. Matyjaszewski, and A. J. Russell, "Permanent, non-leaching antibacterial surfaces-2: How high density cationic surfaces kill bacterial cells," Biomaterials, vol. 28, no. 32, pp. 4870-4879, 2007. 
[50] J. C. Tiller, C.-J. Liao, K. Lewis, and A. M. Klibanov, "Designing surfaces that kill bacteria on contact," Proc. Natl. Acad. Sci., vol. 98, no. 11, pp. 5981-5985, 2001.

[51] N. M. Milović, J. Wang, K. Lewis, and A. M. Klibanov, "Immobilized N-alkylated polyethylenimine avidly kills bacteria by rupturing cell membranes with no resistance developed," Biotechnol. Bioeng., vol. 90, no. 6, pp. 715-722, 2005.

[52] S. B. Lee, R. R. Koepsel, S. W. Morley, K. Matyjaszewski, Y. Sun, and A. J. Russell, "Permanent, nonleaching antibacterial surfaces. 1. Synthesis by atom transfer radical polymerization," Biomacromolecules, vol. 5, no. 3, pp. 877-882, 2004.

[53] J. C. Tiller, S. B. Lee, K. Lewis, and A. M. Klibanov, "Polymer surfaces derivatized with poly (vinyl-Nhexylpyridinium) kill airborne and waterborne bacteria," Biotechnol. Bioeng., vol. 79, no. 4, pp. 465471, 2002.

[54] J. Lin, J. C. Tiller, S. B. Lee, K. Lewis, and A. M. Klibanov, "Insights into bactericidal action of surfaceattached poly (vinyl-N-hexylpyridinium) chains," Biotechnol. Lett., vol. 24, no. 10, pp. 801-805, 2002.

[55] J. Lafarge, N. Kebir, D. Schapman, and F. Burel, "Design of self-disinfecting PVC surfaces using the click chemistry," React. Funct. Polym., vol. 73, no. 11, pp. 1464-1472, 2013.

[56] J. Lin, S. Qiu, K. Lewis, and A. M. Klibanov, "Mechanism of bactericidal and fungicidal activities of textiles covalently modified with alkylated polyethylenimine," Biotechnol. Bioeng., vol. 83, no. 2, pp. 168-172, 2003.

[57] R. Kügler, O. Bouloussa, and F. Rondelez, "Evidence of a charge-density threshold for optimum efficiency of biocidal cationic surfaces," Microbiology, vol. 151, no. 5, pp. 1341-1348, 2005.

[58] E. Gardin, S. Zanna, A. Seyeux, D. Mercier, A. Allion-Maurer, P. Marcus. Early stage of marine biofilm formation on duplex stainless steel, Biointerphases, vol. 15, pp. 041014, 2020.

[59] C. Debbasch, M.D. St Jean, P.J. Pisella, P. Rat, J.M. Warnet, C. Baudouin. Quaternary ammonium cytotoxicity in a human conjunctival cell line. J Fr Ophtalmol., vol 22, no. 9, pp. 950-958, 1999.

[60] D. Fischer, Y. Li, B. Ahlemeyer, J. Krieglstein, T. Kissel, In vitro cytotoxicity testing of polycations: influence of polymer structure on cell viability and hemolysis. Biomaterials, vol 24, no. 7, pp. 11211131, 2003.

[61] T. Eren, A. Som, J. R. Rennie, C. F. Nelson,Y. Urgina, K. Nüsslein, E. B. Coughlin, G. N. Tew. Antibacterial and Hemolytic Activities of Quaternary Pyridinium Functionalized Polynorbornenes. Macromol. Chem. Phys., vol 209, pp. 516-524, 2008.

[62] H. Bouloussa, A.Saleh-mghir, C. Valotteau, C. Cherifi, N. Hafsia, et al.. A Graftable Quaternary Ammonium Biocidal Polymer Reduces Biofilm Formation and Ensures Biocompatibility of Medical Devices. Advanced Materials Interfaces, Wiley, 2021, pp.2001516. 〈10.1002/admi.202001516〉. 〈hal03155802> 


\section{Declaration of interests}

$\bigotimes$ The authors declare that they have no known competing financial interests or personal relationships that could have appeared to influence the work reported in this paper.

$\square$ The authors declare the following financial interests/personal relationships which may be considered as potential competing interests:

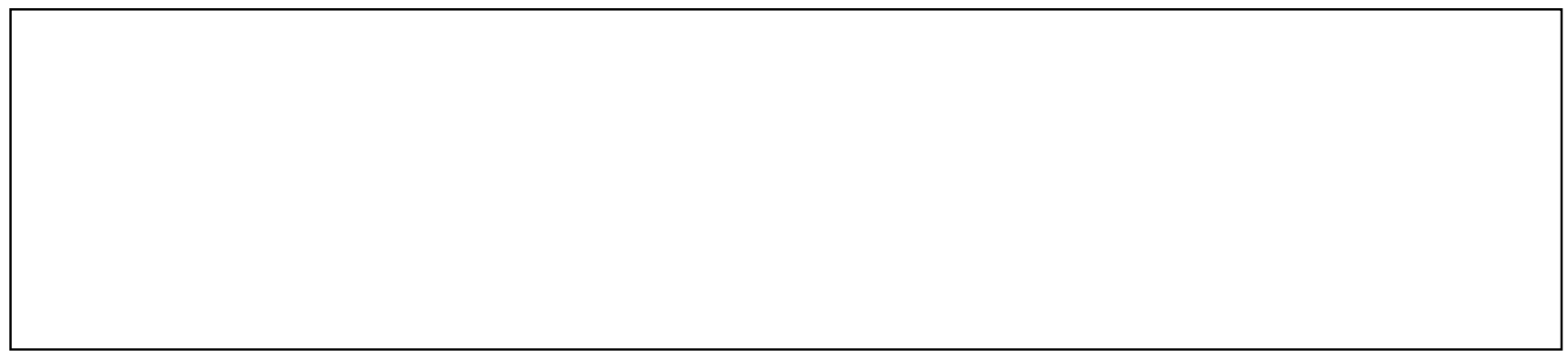


Yuzhen LOU: Investigation, formal analysis, Data Curation, writing.

Damien SCHAPMAN: fluorescence microscopy analysis.

Dimitri MERCIER: XPS analysis and discussion.

Stéphane ALEXANDRE: AFM analysis.

Pascal THEBAULT: methodology, Validation, supervision, reviewing of the first and final drafts of this article.

Fabrice BUREL: Project administration, reviewing of the final draft of this article.

Nasreddine KEBIR: Funding acquisition, project administration, conceptualization, methodology, validation, supervision, writing of the first and final draft of this article. 
- Preparation of PDMS surfaces with high quaternary ammonium density by a 'grafting from' process.

- Use of a direct surface photo-initiated polymerization of vinylbenzyl dimethylbutyl ammonium chloride.

- Obtention of surface charge densities above $10^{17}$ charge $/ \mathrm{cm}^{2}$.

- The obtained surfaces kill efficiently the bacteria on the surface and in suspension. 

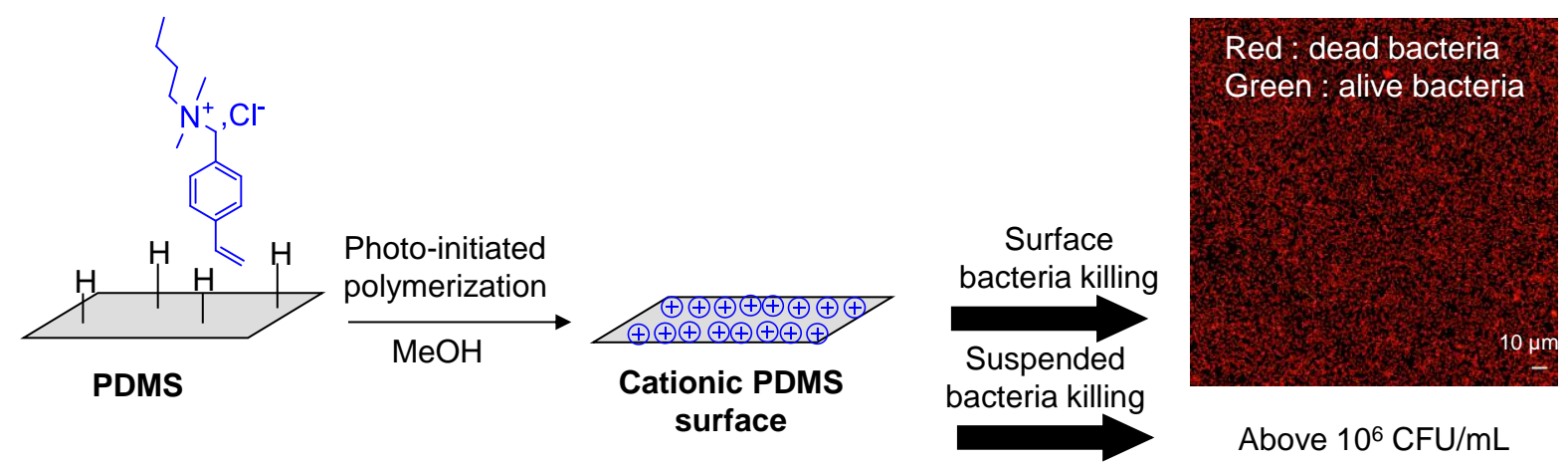


\section{Click here to access/download \\ Supplementary Material
Revised Supporting Information.docx Supplementary Material
Revised Supporting Information.docx Supplementary Material
Revised Supporting Information.docx}

